(2) Open Access Full Text Article

ORIGINAL RESEARCH

\title{
A retrospective analysis of dermatological problems in a hematology ward
}

This article was published in the following Dove Press journal:

Clinical, Cosmetic and Investigational Dermatology

28 May 2013

Number of times this article has been viewed

\section{HY Koh}

Dermatology Unit, Singapore General Hospital, Singapore
Correspondence: HY Koh

Singapore General Hospital,

Outram Road, Singapore 169608,

Republic of Singapore

Tel +6562223322

Fax+65 6224922

Email kohhy13@outlook.com
Background: Skin problems are common in patients with hematological disorders Dermatologists play an important role in providing consultative service to other medical specialties. While most requests for dermatologic consultations are for common skin conditions, challenging scenarios and diagnostic dilemmas are frequently encountered, especially in acutely ill, immunocompromised patients.

Aim: To characterize the profile of dermatological problems encountered in a hematology unit in a tertiary hospital, and to delineate clinical features that may help to distinguish cutaneous adverse drug reactions from toxic erythema of chemotherapy.

Materials and methods: A retrospective study was conducted reviewing all inpatient referrals for dermatology consultations from the hematology unit during a 6-month period from January 2010 to June 2010, at the largest multidisciplinary tertiary hospital in Singapore.

Results: Of the 692 referrals for dermatology consultation, 58 (8.3\%) came from the hematology department. A total of 60 dermatological diagnoses were made. Most patients were referred for primary dermatological disorders $(43.33 \%, \mathrm{n}=26)$. The most common diagnoses within this category were cutaneous infections $(15 \%, \mathrm{n}=9)$ and dermatitis $(13.33 \%, \mathrm{n}=8)$. Cutaneous adverse drug reactions $(16.67 \%, \mathrm{n}=10)$ and toxic erythema of chemotherapy $(10 \%, \mathrm{n}=6)$ were also frequently encountered. We could not identify any distinctive clinical feature that may help to differentiate the two conditions.

Conclusion: Our study reinforces the importance of inpatient medical dermatology in terms of both service and education to nondermatologists, who continue to face difficulties diagnosing common skin disorders. Cutaneous adverse drug reactions and toxic erythema of chemotherapy are clinically similar and difficult to differentiate. Larger prospective studies are needed to examine this problem.

Keywords: dermatological problems, hematology, oncology, toxic erythema, chemotherapy, cutaneous adverse drug reactions

\section{Introduction}

While dermatologic practice occurs primarily in the outpatient setting, dermatologists also provide essential consultative services to the care of inpatients admitted to other medical disciplines. A dermatologic consult often leads to a revision to the original diagnosis made by the referring physician, ordering of skin directed investigations, and changes in treatment of the skin disease. ${ }^{1-7}$ Previous studies have shown that the discipline of Medicine make the most requests for inpatient dermatologic services. ${ }^{1,4,7,8}$ We have observed in our institution that patients from the Hematology ward form a significant portion of referrals to the Dermatologic Unit. Cutaneous eruptions in 
this cohort of acutely ill, immunocompromised patients on multiple medications can be particularly challenging to the dermatologist. The objective of this study was to characterize the profile of dermatological issues frequently encountered in the Hematology ward.

\section{Materials and methods}

This was a retrospective study conducted at the largest, multidisciplinary tertiary hospital in Singapore (Singapore General Hospital, Singapore). The Hematology Department in this hospital regularly receives patients from other institutions in the region and has an active bone marrow transplantation program. We reviewed all inpatient referrals for Dermatology consultations made from the Department of Hematology during a 6-month period from January 2010 to June 2010. Medical records (both written and electronic) of these consultations stored in the hospital were examined.

\section{Results}

A total of 692 inpatient referrals were made to the Dermatology Unit in the study period. Of these, 58 (8.3\%) were from the Hematology department. There were slightly more males $(\mathrm{n}=34 ; 58.6 \%)$ than females $(\mathrm{n}=24 ; 41.4 \%)$, and the mean age of patients was 55.5 years (range: $13-90$ years). The racial composition included 47 Chinese (81.0\%), 8 Malays (13.8\%), 2 Indians (3.4\%) and 1 "Others" (1.7\%). It was a heterogeneous group with various underlying hematological disorders (Table 1). More than half of the patients had myeloid or lymphoid malignancies.

Table I Underlying hematological diagnoses

\begin{tabular}{|c|c|}
\hline Hematological condition & Number of cases (\%) \\
\hline \multicolumn{2}{|l|}{ Myeloid neoplasms } \\
\hline Acute myeloid leukemia & $19(32.76 \%)$ \\
\hline Acute biphenotypic leukemia & I (I.72\%) \\
\hline Myeloproliferative disease & $6(10.35 \%)$ \\
\hline Myelodysplastic disease & $3(5.17 \%)$ \\
\hline \multicolumn{2}{|l|}{ Lymphoid neoplasms } \\
\hline B-cell neoplasms & $12(20.69 \%)$ \\
\hline T-cell and NK-cell neoplasms & $4(6.90 \%)$ \\
\hline Acute lymphoblastic leukemia & $4(6.90 \%)$ \\
\hline Hodgkin lymphoma & I (I.72\%) \\
\hline Lymphoma (unclassified) & I (I.72\%) \\
\hline Post-transplant lymphoproliferative & I (I.72\%) \\
\hline \multicolumn{2}{|l|}{ disorder (PTLD) } \\
\hline Hypereosinophilic syndrome & I (I.72\%) \\
\hline Amegakaryocytic thrombocytopenia & I (I.72\%) \\
\hline Medullary glioma & I (I.72\%) \\
\hline Others (anemia, thrombocytopenia, & $3(5.17 \%)$ \\
\hline \multicolumn{2}{|l|}{ infectious mononucleosis) } \\
\hline Total & $58(100 \%)$ \\
\hline
\end{tabular}

Abbreviation: NK, natural killer.
A total of 60 dermatologic conditions were diagnosed in the 58 patients (Table 2). Most patients had a primary dermatologic condition, with dermatitis (13.3\%) and infective disorders (15\%) being most common. Different types of dermatitis were represented, ranging from asteatotic to seborrhoeic and nummular eczema. Infections were caused by viruses (eg, infectious mononucleosis), fungi (eg, candidiasis) and bacteria (eg, furuncles). Reactivation of latent herpes simplex giving rise to herpes labialis, was the most common infective condition in our study. Complications of thrombocytopenia (petechiae and purpura) were familiar to the hematologists, and the few cases seen were referred to exclude cutaneous drug eruptions or vasculitis.

Table 2 Dermatologic conditions diagnosed in hematology inpatients

\begin{tabular}{|c|c|}
\hline Dermatological condition & Number of cases (\%) \\
\hline Primary dermatological disease & $26(43.33 \%)$ \\
\hline Eczematous dermatitis & $8(13.33 \%)$ \\
\hline Asteatotic eczema & $2(3.33 \%)$ \\
\hline Contact dermatitis & $2(3.33 \%)$ \\
\hline Eczematous dermatitis, unspecified & I (I.67\%) \\
\hline Nummular eczema & I (I.67\%) \\
\hline Seborrhoeic dermatitis & $2(3.33 \%)$ \\
\hline Infective disorders & $9(15.00 \%)$ \\
\hline Cutaneous candidiasis & $\mathrm{I}(\mathrm{I} .67 \%)$ \\
\hline Ecthyma gangrenosum & $2(3.33 \%)$ \\
\hline Furunculosis, multiple & I (1.67\%) \\
\hline Herpes labialis & $3(5.00 \%)$ \\
\hline Infective mononucleosis & I (I.67\%) \\
\hline Pityriasis vesicolor & I (I.67\%) \\
\hline Others & $9(15.00 \%)$ \\
\hline Chronic urticaria & I (I.67\%) \\
\hline Lipoma & I (I.67\%) \\
\hline Neutrophilic dermatosis & I (I.67\%) \\
\hline Prurigo nodularis & $\mathrm{I}(\mathrm{I} .67 \%)$ \\
\hline Psoriasis & $\mathrm{I}(1.67 \%)$ \\
\hline Steroid acne & $2(3.33 \%)$ \\
\hline Arthropod bite reaction & I (I.67\%) \\
\hline Seborrhoeic keratosis & $\mathrm{I}(\mathrm{I} .67 \%)$ \\
\hline Hematologic disorders & $4(6.67 \%)$ \\
\hline Petechiae and purpura & $4(6.67 \%)$ \\
\hline Toxic erythema of chemotherapy (TEC) & $6(10.00 \%)$ \\
\hline Neutrophilic eccrine hidradenitis & $\mathrm{I}(\mathrm{I} .67 \%)$ \\
\hline Palmar-plantar erythema & $2(3.33 \%)$ \\
\hline TEC, unspecified & $3(5.00 \%)$ \\
\hline Cutaneous adverse drug reaction & $10(16.67 \%)$ \\
\hline Exanthem & $9(15.00)$ \\
\hline $\begin{array}{l}\text { Stevens-Johnson syndrome/ } \\
\text { toxic epidermal necrolysis overlap }\end{array}$ & I (I.67\%) \\
\hline TEC versus drug exanthem & $4(6.67 \%)$ \\
\hline Viral versus drug-related exanthem & $2(3.33 \%)$ \\
\hline Cutaneous adverse effects of EGFR inhibitors & I (I.67\%) \\
\hline Lymphoma cutis & I (I.67\%) \\
\hline Unknown & $6(10.00 \%)$ \\
\hline Total & $60(100 \%)$ \\
\hline
\end{tabular}

Abbreviation: EGFR, epidermal growth factor receptor. 
Unsurprisingly, there were a significant number of cases of cutaneous adverse drug reactions (CADRs). Hematology inpatients were often acutely sick and on multiple medications for treatment of the underlying disease and its complications. Many of these drugs, such as beta-lactam and sulfa-based antibiotics and allopurinol, are frequently associated with CADRs.

Six patients were diagnosed with toxic erythema of chemotherapy (TEC), a term coined by Bolognia et al in 2008. ${ }^{9}$ It encompasses a group of overlapping toxic reactions in the skin due to chemotherapeutic agents that are (1) not allergic in nature, (2) resolve spontaneously after chemotherapy is stopped, (3) usually require only symptomatic treatment, and (4) do not preclude the use of the same causative agent in the future. The major entities within the spectrum of TEC include Cytarabine (Ara-C) ears, palmar-plantar erythema, neutrophilic eccrine hidradenitis (NEH) and eccrine squamous syringometaplasia (ESS). TEC often occurs at a critical period after administration of chemotherapy, when the patient is receiving multiple antibiotics for neutropenic infection, and at risk for CADR and cutaneous infections. Differentiating TEC from CADR or cutaneous infection can be difficult - in our study, 4 cases were given a provisional diagnosis of "TEC versus drug exanthem" and 2 cases were diagnosed as "exanthem - viral versus drug-related".

\section{Comparison of cases of drug exanthema versus TEC}

Since the term TEC was introduced, there had been few studies on the clinical features that may help to distinguish it from other differential diagnoses (such as CADR), which often occur in the same clinical setting. We sought to clarify this issue by analyzing the cases of drug exanthem and TEC in our study (Table 3). Patients with TEC had, on average, a younger age and a shorter duration between the onset of chemotherapy to the eruption of rash. However, there is a wide range of values, which overlapped with those of patients who had drug exanthem. There was no obvious difference in the presence of neutropenia or intensity of itch amongst the groups.

Apart from two cases of palmar-plantar erythema, the remaining four cases of suspected TEC had generalized pruritic, exanthematous eruptions which made them clinically similar to drug or viral induced exanthems. In one patient, the cutaneous eruption displayed an intertriginous distribution, which in our experience was a common and distinctive feature in TEC. ${ }^{9}$

The four patients with generalized TEC received the following chemotherapeutic agents prior to onset of rash: idarubicin plus cytarabine (as induction chemotherapy), high-dose intermittent cytarabine (HiDAC) and fludarabine, cytarabine plus filgrastim (FLAG). Apart from FLAG, none of the regimens are unique to TEC patients in our study many of the patients with CADR had received similar medications either in the current or previous admissions.

Amongst the patients with drug exanthem, suspected causative drugs were mostly antimicrobials, including: beta-lactam antibiotics, piperacillin - tazobactam, bactrim, ciprofloxacin, amikacin, polymyxin B and lamivudine. Other suspected medications included omeprazole and amiloride. In six cases, this resulted in cessation of the suspected drug.

Table 3 Characteristics of cases of TEC and drug exanthem

\begin{tabular}{|c|c|c|c|c|}
\hline & $\begin{array}{l}\text { Palmar-plantar erythema } \\
(n=2)\end{array}$ & $\begin{array}{l}\text { TEC } \\
(n=4)\end{array}$ & $\begin{array}{l}\text { Drug exanthem } \\
(n=9)\end{array}$ & $\begin{array}{l}\text { TEC vs drug exanthem } \\
(n=4)\end{array}$ \\
\hline Mean age in years & $\begin{array}{l}31.0 \\
\text { (range 19-43) }\end{array}$ & $\begin{array}{l}47.5 \\
\text { (range 35-59) }\end{array}$ & $\begin{array}{l}62.6 \\
\text { (range 46-85) }\end{array}$ & $\begin{array}{l}56.3 \\
\text { (range 52-62) }\end{array}$ \\
\hline Male:female ratio & $\mathrm{I}: \mathrm{I}$ & $3: 1$ & $6: 3$ & $\mathrm{I}: 3$ \\
\hline $\begin{array}{l}\text { Mean duration between } \\
\text { chemotherapy and onset of rash }\end{array}$ & $29 *$ & $\begin{array}{l}9.5 \text { days } \\
\text { (range } 3-23 \text { ) }\end{array}$ & $\begin{array}{l}\text { I6.8 days } \\
\text { (range } 4-24)^{* *}\end{array}$ & $\begin{array}{l}\text { I I.5 days } \\
\text { (range } 2-20)\end{array}$ \\
\hline $\begin{array}{l}\text { Presence of neutropenia at time } \\
\text { of rash }\end{array}$ & $\mathrm{I} / 2$ & $3 / 4$ & $6 / 8 * * *$ & $3 / 4$ \\
\hline \multicolumn{5}{|l|}{ Intensity of itch } \\
\hline None & 2 & 2 & 1 & 2 \\
\hline Mild & - & 2 & 2 & 2 \\
\hline Moderate & - & - & - & - \\
\hline Severe & - & - & 2 & - \\
\hline Unspecified & - & - & 4 & - \\
\hline $\begin{array}{l}\text { Mean number of drugs at onset } \\
\text { of rash }\end{array}$ & NA & $\begin{array}{l}8 \\
\text { (range 6-10) }\end{array}$ & $\begin{array}{l}6.7 \\
\text { (range 3-15) }\end{array}$ & $\begin{array}{l}8.5 \\
\text { (range 5-15) }\end{array}$ \\
\hline
\end{tabular}

Notes: *Data available only from I patient; **data available only for 6 patients; ${ }^{* * *}$ data available only for 8 patients.

Abbreviations: NA, not available; TEC, toxic erythema of chemotherapy. 
In cases where the patient was labeled as "TEC versus drug exanthem", no culprit drugs were named, but two patients still had their antimicrobial agents changed in view of the cutaneous eruption.

None of the four TEC patients had a skin biopsy, either because a clinical diagnosis was deemed sufficient, the patient declined a biopsy or due to the primary physician's concerns about the risks of biopsy in the setting of neutropenia and thrombocytopenia.

\section{Discussion}

Skin problems are common in inpatients with underlying hematological or oncological diseases. In a random review of patients admitted to a Hematology-Oncology unit, Pearson et al found mucocutaneous disorders in $88 \%$ of cases seen. ${ }^{10}$ The most common findings in their study were alopecia, mucositis, palm and sole erythema associated with bone marrow transplantation and drug allergies. In contrast, most of our patients were referred for primary dermatological issues. This is consistent with findings from previous studies, including one from our institution, that non-dermatologists face difficulties diagnosing common dermatoses. ${ }^{1-3,5,6,8} \mathrm{~A}$ dermatologic consultation resulted in changes in diagnosis and management in $60 \%$ to $77 \%$ of times. ${ }^{1,3,6}$ This underscores the importance and continuing demand for inpatient medical dermatology. A "dermatology hospitalist" model has been proposed to improve inpatient dermatologic care and further dermatologic education of students and consulting physicians. ${ }^{11}$

Evaluation of cutaneous eruptions in a hematologiconcologic cohort can be challenging. Apart from common dermatologic issues, these patients are at risk for adverse reactions to chemotherapeutic agents, atypical infections, paraneoplastic syndromes, nutritional deficiencies, hypersensitivity reactions and cutaneous metastases from their primary neoplasm.

A typical scenario in the setting of the Hematology ward is a patient who developed a rash while on multiple antibiotics for treatment of neutropenic sepsis, which set in after chemotherapy. Most commonly, the rash had developed fairly rapidly, is pruritic, exanthematous and generalized. Possible diagnoses include cutaneous infections (both primary and embolic), CADR, TEC and graft versus host disease (GVHD), if transplantation had taken place. Management strategies required for these conditions are markedly different. Infections in an immunocompromised host need to be treated aggressively with antibiotics. Treatment of GVHD includes increased immunosuppression, for example with systemic steroids. CADR may progress to severe cutaneous adverse reactions (SCAR) if the offending drug (most often an antimicrobial) is not stopped promptly, whereas TEC often requires only supportive treatment and will resolve spontaneously.

A skin biopsy is one of the most valuable investigations in dermatology. Morbilliform drug eruptions often display mild perivascular lymphocytic infiltrates and few necrotic keratinocytes within the epidermis. Cutaneous infections may show lymphocytic and/or neutrophilic infiltrates in the dermis with the causative microorganism identifiable by appropriate stains or culture. The major histologic features of GVHD include basal layer vacuolization, presence of apoptotic keratinocytes sometimes adjacent to lymphocytes (satellite cell necrosis), exocytosis of mononuclear cells and focal spongiosis. The results of a biopsy must be interpreted within the clinical context, especially when histologic features are non-specific or show significant overlap amongst possible differential diagnoses. ${ }^{12}$ This highlights the importance in developing a discriminative eye to subtle clinical differences between diseases with similar characteristics.

In our study, we also looked for clinical features that may guide the clinician to differentiate TEC from CADR, a common clinical problem. A delay in diagnosis may be deleterious to the patient, whether in terms of unnecessary stoppage of antibiotics in cases of TEC, or inappropriate continuation of offending drugs in CADR. We were unable to find major differences in terms of patient characteristics, degree of pruritus, morphology or distribution of rash, presence of fever or neutropenia, and type of chemotherapy regimen between the two groups in our patients. One patient with TEC was noted to have an intertriginous distribution of his rash which has been reported to be a feature of TEC. ${ }^{9}$

Limitations of our study include the small number of patients, and its retrospective nature where some data was not adequately recorded and incomplete. The paucity of histological information also limited the interpretation of our data. Most of the dermatological conditions were diagnosed clinically, and a biopsy was not deemed necessary. In other situations, the patients declined biopsy out of concern for bleeding or infection. We did not have complete data on the presence of neutropenia in our patients, and could not examine if there was a relationship between blood anomalies and the occurrence of inflammatory or infective dermatoses.

\section{Conclusion}

Hematology inpatients suffer from common dermatological diseases, as well as cutaneous eruptions unique to 
their situation. TEC and CADR remain difficult to differentiate purely on clinical grounds in this group. Larger studies of a prospective nature may shed light on the useful clinical features that may guide the dermatologist faced with this dilemma.

\section{Disclosure}

The author reports no conflicts of interest in this work.

\section{References}

1. Falanga V, Schachner LA, Rae V, et al. Dermatologic consultations in the hospital setting. Arch Dermatol. 1994;130(8):1022-1025.

2. Maza A, Berbis J, Gaudy-Marqueste C, et al. Evaluation of dermatology consultations in a prospective multicenter study involving a French teaching hospital. Ann Dermatol Venereol. 2009;136(3):241-248.

3. Tay LK, Lee HY, Thirumoorthy T, Pang SM. Dermatology referrals in an East Asian tertiary hospital: a need for inpatient medical dermatology. Clin Exp Dermatol. 2011;36(2):129-134.

4. Bauer J, Maroon M. Dermatology inpatient consultations: a retrospective study. J Am Acad Dermatol. 2010;62(3):518-519.
5. Itin PH. Dermatologic consultations in the hospital ward: the skin, an interdisciplinary organ. Dermatology (Basel). 2009;219(3):193-194.

6. Davila M, Christenson LJ, Sontheimer RD. Epidemiology and outcomes of dermatology in-patient consultations in a Midwestern US university hospital. Dermatol Online J. 2010;16(2):12.

7. Mancusi S, Festa Neto C. Inpatient dermatological consultations in a university hospital. Clinics (Sao Paulo). 2010;65(9):851-855.

8. Peñate Y, Guillermo N, Melwani P, Martel R, Borrego L. Dermatologists in hospital wards: an 8-year study of dermatology consultations. Dermatology (Basel). 2009;219(3):225-231.

9. Bolognia JL, Cooper DL, Glusac EJ. Toxic erythema of chemotherapy: a useful clinical term. J Am Acad Dermatol. 2008;59(3):524-529.

10. Pearson IC, Sirohi B, Powles R, Treleaven J, Mortimer PS. The impact on resources of prevalence and nature of skin problems in a modern intensive haemato-oncology practice. Hematology. 2004;9(5-6):415-423.

11. Fox LP, Cotliar J, Hughey L, Kroshinsky D, Shinkai K. Hospitalist dermatology. J Am Acad Dermatol. 2009;61(1):153-154.

12. Rajaratnam R, Smith AG, Biswas A, Stephens M. The value of skin biopsy in inflammatory dermatoses. Am J Dermatopathol. 2009;31(4):350-353.
Clinical, Cosmetic and Investigational Dermatology

\section{Publish your work in this journal}

Clinical, Cosmetic and Investigational Dermatology is an international, peer-reviewed, open access, online journal that focuses on the latest clinical and experimental research in all aspects of skin disease and cosmetic interventions. All areas of dermatology will be covered; contributions will be welcomed from all clinicians and

\section{Dovepress}

basic science researchers globally. This journal is indexed on CAS. The manuscript management system is completely online and includes a very quick and fair peer-review system, which is all easy to use. Visit http://www.dovepress.com/testimonials.php to read real quotes from published authors.

Submit your manuscript here: http://www.dovepress.com/clinical-cosmetic-and-investigational-dermatology-journal 